\title{
Kesehatan hidung siswa-siswi Sekolah Menengah Pertama Negeri 8 Manado
}

\author{
${ }^{1}$ Pety T. Sari R. \\ ${ }^{2}$ Steward K. Mengko \\ ${ }^{2}$ Augustien Y. Tamus
}

\author{
${ }^{1}$ Kandidat Skripsi Fakultas Kedokteran Universitas Sam Ratulangi Manado \\ ${ }^{2}$ Bagian Telinga Hidung Tenggorokan-Bedah Kepala Leher Fakultas Kedokteran \\ Universitas Sam Ratulangi Manado \\ Email: petytunjungsari@gmail.com
}

\begin{abstract}
Environmental factors have great influence on nose function. This study was aimed to obtain the nose health status of students at SeMP negeri 8 (Junior High School) Manado. This was a descriptive observational study with a cross sectional design. Respondents were students of SMP Negeri 8. There were 31 respondents consisted of 11 males and 21 females. The examination showed normal results of nasal cavity, concha, mucosa, secret, and postnasal drips. The examination of septum showed septal deviation of $3.13 \%$ in the right nostril. Conclusion: The nose health status of the students at SMP Negeri 8 was categorized as good.

Keywords: health survey, nose examination.
\end{abstract}

\begin{abstract}
Abstrak: Lingkungan merupakan faktor terbesar yang mempengaruhi kesehatan. Penelitian ini bertujuan untuk memperoleh gambaran kesehatan hidung pada siswa-siswi Sekolah Menengah Pertama Negeri 8 Manado. Jenis penelitian ialah deskriptif observasional dengan desain potong lintang. Responden penelitian ialah siswa-siswi kelas IX C SMP Negeri 8 Manado. Terdapat 32 responden dalam penelitian ini terdiri dari 21 perempuan dan 11 lakilaki. Hasil normal ditemukan pada semua pemeriksaan kavum nasal, konka, mukosa, sekret, dan post nasal drip. Pada pemeriksaan septum, deviasi septum ditemukan 3,13\% pada hidung kanan. Simpulan. Status kesehatan hidung siswa-siswi SMP Negeri 8 Manado baik.
\end{abstract}

Kata kunci: survei kesehatan, pemeriksaan fisik hidung

Dalam Undang-Undang Kesehatan No. 23 tahun 1992, kesehatan secara lebih kompleks didefinisikan sebagai keadaan sejahtera dari badan, jiwa, dan sosial yang memungkinkan setiap orang hidup produktif secara sosial dan ekonomi. Dengan demikian, upaya kesehatan yang dilakukan mengarahkan masyarakat mencapai kesehatan yang cukup agar dapat hidup produktif. ${ }^{1}$ Faktor kesehatan dapat mempengaruhi turunnya kualitas tingkat pendidikan. Semakin banyak anak sekolah yang sakit, semakin rendah pula kualitas pendidikan yang akan dicapai oleh anak tersebut. $^{2}$
Hidung merupakan salah satu organ yang penting dan seharusnya mendapat perhatian lebih dari biasanya. Hidung juga merupakan salah satu organ pelindung tubuh terpenting terhadap lingkungan yang tidak menguntungkan. ${ }^{3}$

Hidung dan sinus paranasal mempunyai beberapa fungsi fisiologis yaitu sebagai indra penghidu karena terdapatnya mukosa olfaktorius dan reservoir udara untuk menampung stimulus penghidu, fungsi respirasi untuk mengatur udara inhalasi agar dapat digunakan oleh paruparu, mempengaruhi refleks tertentu pada paru-paru dan fungsi fonetik yang berguna 
untuk resonansi suara, membantu proses bicara dan mencegah hantaran suara sendiri melalui konduksi tulang. ${ }^{4}$

Data yang didapatkan dari Departemen Kesehatan Republik Indonesia (DEPKES RI) tahun 2003 menyebutkan bahwa penyakit hidung dan sinus berada pada urutan ke-25 dari 50 pola penyakit peringkat utama atau sekitar 102.817 penderita rawat jalan di rumah sakit. ${ }^{5}$

Penyakit-penyakit yang dapat timbul di hidung antara lain rinitis alergi maupun vasomotor, sinusitis, polip hidung, deviasi septum dan epistaksis. Penyakit-penyakit ini dapat ditemukan pada semua umur, terkhusus pada anak-anak usia sekolah dan remaja. Bersin, pilek, hidung gatal atau hidung yang terasa buntu yang sering terjadi pada pagi hari merupakan salah satu gelaja dari rinitis alergi. Rinitis alergi adalah salah satu contoh penyakit alergi yang umumnya diderita pada anak usia sekolah.

Study dari International of Asthma and Allergic in Childhood (ISAAC) melaporkan bahwa prevalensi rinitis alergi pada anak dan remaja menunjukkan variabilitas besar diseluruh dunia, tetapi hanya berpengaruh $15 \%$ di Indonesia, pada anak rentang usia 6-7 tahun sebanyak 3,6\% dan pada remaja rentang usia 13-14 tahun sebanyak $6,4 \% .^{6,7}$

Penelitian ini bertujuan untuk untuk mengetahui gambaran kesehatan hidung pada remaja dengan melakukan survei kesehatan hidung pada siswa-siswi Sekolah Menengah Pertama Negeri 8 Manado.

\section{METODE PENELITIAN}

Jenis penelitian yang digunakan ialah deskriptif observasional dengan desain potong lintang. Penelitian dilakukan pada tanggal 14 Oktober 2016 di Sekolah Menengah Pertama Negeri 8 Manado. Populasi penelitian ialah siswa-siswi SMP Negeri 4 Pineleng sedangkan responden penelitian ialah siswa-siswi kelas IX C SMP Negeri 8 Manado.

Pemeriksaan hidung responden dilakukan secara langsung. Data hasil pemeriksaan dimasukkan pada tabel pemeriksaan THT yang telah disusun dengan Microsoft Word dan data diolah menggunakan Microsoft Excel.

\section{HASIL PENELITIAN}

Pada penelitian di SMP Negeri 8 Manado kelas IX C, persentase jenis kelamin terbanyak yaitu perempuan berjumlah 21 siswa $(65,63 \%)$ dan sisanya laki-laki berjumlah 11 siswa $(34,37 \%)$ (Tabel 1).

Tabel 1. Distribusi berdasarkan jenis kelamin siswa-siswi SMP Negeri 8 Manado.

\begin{tabular}{ccc}
\hline Jenis & $\mathbf{n}$ & $\mathbf{( \% )}$ \\
\hline Perempuan & 21 & 65,63 \\
Laki-laki & 11 & 34.37 \\
Total & 32 & 100 \\
\hline
\end{tabular}

Tabel 2 memperlihatkan bahwa responden terbanyak berusia 13 tahun (50\%), diikuti oleh yang berusia 14 tahun $(43,7 \%)$, dan yang berusia 15 tahun $(6,3 \%)$.

Tabel 2. Distribusi berdasarkan usia siswasiswi SMP Negeri 8 Manado.

\begin{tabular}{ccc}
\hline Usia & $\mathbf{n}$ & $\mathbf{( \% )}$ \\
\hline 13 tahun & 16 & 50 \\
14 tahun & 14 & 43,7 \\
15 tahun & 2 & 6,3 \\
Total & 32 & 100 \\
\hline
\end{tabular}

Tabel 3 memperlihatkan hasil kavum nasal kiri maupun kanan semuanya lapang $(100 \%)$. Pada keduanya tidak ditemukan kavum yang sempit maupun adanya massa dalam kavum.

Tabel 3. Distribusi keadaan kavum nasal siswa-siswi Sekolah Menengah Pertama Negeri 8 Manado

\begin{tabular}{ccccc}
\hline \multirow{2}{*}{ Kavum } & \multicolumn{2}{c}{ n } & \multicolumn{2}{c}{$(\%)$} \\
\cline { 2 - 5 } Nasal & Kiri & Kanan & Kiri & Kanan \\
\hline Lapang & 32 & 32 & $100 \%$ & $100 \%$ \\
Sempit & 0 & 0 & 0 & 0 \\
Massa & 0 & 0 & 0 & 0 \\
Total & 32 & 32 & $100 \%$ & $100 \%$ \\
\hline
\end{tabular}


Tabel 4 memperlihatkan hasil konka kiri maupun kanan semuanya normal (100\%). Pada keduanya tidak ditemukan konka yang edema, hiperemis, pucat, hipertrofi, ataupun atrofi.

Tabel 4. Distribusi keadaan konka siswa-siswi SMP Negeri 8 Manado

\begin{tabular}{ccccc}
\hline \multirow{2}{*}{ Keadaan } & \multicolumn{2}{c}{$\mathbf{n}$} & \multicolumn{2}{c}{$(\%)$} \\
\cline { 2 - 5 } & Kiri & Kanan & Kiri & Kanan \\
\hline Normal & 32 & 32 & 100 & 100 \\
Edema & 0 & 0 & 0 & 0 \\
Edema + & 0 & 0 & 0 & 0 \\
Hiperemis & & & & \\
Pucat & 0 & 0 & 0 & 0 \\
Hipertrofi & 0 & 0 & 0 & 0 \\
Atrofi & 0 & 0 & 0 & 0 \\
Total & 32 & 32 & 100 & 100 \\
\hline
\end{tabular}

Tabel 5 memperlihatkan hasil mukosa hidung kiri maupun kanan semuanya normal (100\%). Pada keduanya tidak ditemukan adanya kelainan mukosa seperti hiperemis dan livide (Tabel 5)

Tabel 5. Distribusi keadaan mukosa siswasiswi SMP Negeri 8 Manado

\begin{tabular}{ccccc}
\hline \multirow{2}{*}{ Keadaan } & \multicolumn{2}{c}{$\mathbf{N}$} & \multicolumn{2}{c}{$(\boldsymbol{\%})$} \\
\cline { 2 - 5 } & Kiri & Kanan & Kiri & Kanan \\
\hline Normal & 32 & 32 & 100 & 100 \\
Hiperemis & 0 & 0 & 0 & 0 \\
Livide & 0 & 0 & 0 & 0 \\
Total & 32 & 32 & 100 & 100 \\
\hline
\end{tabular}

Tabel 6 memperlihatkan hasil pemeriksaan sekret hidung kiri maupun kanan semuanya normal (100\%). Pada keduanya tidak ditemukan adanya sekret yang serous, mukoid, maupun purulen.

Tabel 7 memperlihatkan hasil pemeriksaan septum sebagian besar normal dengan persentase pada hidung kiri $100 \%$, dan pada hidung kanan $96,87 \%$. Terdapat kelainan septum berupa deviasi pada hidung kanan dengan persentase 3,13\%, sedangkan hidung kiri tidak ada deviasi. Tidak terdapat kelainan septum lainnya seperti abses dan hematoma.
Tabel 6. Distribusi keadaan sekret siswa-siswi SMP Negeri 8 Manado.

\begin{tabular}{ccccc}
\hline \multirow{2}{*}{ Keadaan } & \multicolumn{2}{c}{$\mathbf{n}$} & \multicolumn{2}{c}{$(\boldsymbol{\%})$} \\
\cline { 2 - 5 } & Kiri & Kanan & Kiri & Kanan \\
\hline Tidak & 32 & 32 & 100 & 100 \\
Serous & 0 & 0 & 0 & 0 \\
Mukoid & 0 & 0 & 0 & 0 \\
Purulen & 0 & 0 & 0 & 0 \\
Total & 32 & 32 & 100 & 100 \\
\hline
\end{tabular}

Tabel 7. Distribusi keadaan septum siswa-siswi SMP Negeri 8 Manado.

\begin{tabular}{ccccc}
\hline \multirow{2}{*}{ Keadaan } & \multicolumn{2}{c}{$\mathbf{n}$} & \multicolumn{2}{c}{$(\boldsymbol{\%})$} \\
\cline { 2 - 5 } & Kiri & Kanan & Kiri & Kanan \\
\hline Normal & 32 & 31 & 100 & 96,87 \\
Deviasi & 0 & 1 & 0 & 3,13 \\
Abses & 0 & 0 & 0 & 0 \\
Hematoma & 0 & 0 & 0 & 0 \\
Total & 32 & 32 & 100 & 100 \\
\hline
\end{tabular}

Tabel 8 memperlihatkan hasil pemeriksaan post nasal drip dan didapatkan semua hasil normal (100\%).

Tabel 8. Distribusi keadaan post nasal drip siswa-siswi SMP Negeri 8 Manado.

\begin{tabular}{ccccc}
\hline \multirow{2}{*}{ Keadaan } & \multicolumn{2}{c}{$\mathbf{n}$} & \multicolumn{2}{c}{$(\boldsymbol{\%})$} \\
\cline { 2 - 5 } & Kiri & Kanan & Kiri & Kanan \\
\hline Tidak ada & 32 & 32 & 100 & 100 \\
Ada & 0 & 0 & 0 & 0 \\
Total & 32 & 32 & 100 & 100 \\
\hline
\end{tabular}

\section{BAHASAN}

Pada penelitian kesehatan hidung yang dilakukan pada siswa-siswi SMP Negeri 8 Manado terdapat 32 responden dan yang terbanyak ialah perempuan $(65,63 \%)$. Pada pemeriksaan yang dilakukan pada semua responden terdapat hasil normal yang terbanyak.

Pada pemeriksaan didapatkan hasil kavum nasal kiri maupun kanan semuanya lapang (100\%) untuk semua responden dan pada keduanya tidak ditemukan kavum yang sempit maupun adanya massa dalam kavum. Penelitian sebelumnya yang dilakukan oleh Legoh $^{8}$ terhadap siswasiswi SD Inpres 10/73 Pandu mendapatkan hasil kedua kavum nasal baik kiri dan 
kanan semua normal dan lapang (100\%) dan tidak ditemukan kelainan kavum nasal yang sempit ataupun adanya massa. Kavum nasi dapat menjadi sempit disebabkan oleh banyak penyebab, salah satunya ialah polip nasi. Polip nasi adalah massa lunak yang mengandung banyak cairan di dalam rongga hidung, berwarna putih keabuabuan, yang terjadi akibat inflamasi mukosa. Polip dapat timbul pada laki-laki maupun perempuan dari usia anak-anak sampai usia lanjut. ${ }^{9}$

Pada pemeriksaan di SMP Negeri 8 Manado didapatkan hasil konka kiri maupun kanan semuanya normal (100\%) dan pada keduanya tidak ditemukan konka yang edema, hiperemis, pucat, hipertrofi, ataupun atrofi. Pada penelitian sebelumnya yang dilakukan oleh Legoh $^{8}$ terhadap siswa-siswi SD Inpres 10/73 Pandu, didapatkan hasil yang sama pada kedua konka nasal baik kiri dan kanan. Keadaan konka normal merupakan hasil yang terbanyak yaitu berjumlah 14 anak $(77,78 \%)$. Keadaan abnormal terbanyak yang ditemukan pada kedua konka ialah hiperemis disertai edema dengan jumlah 4 anak (22,22\%). Keadaan abnormal lain yang ditemukan pada kedua konka nasal yaitu hiperemis dengan jumlah 1 anak $(5,56 \%)$ sedangkan keadaan seperti edema, pucat, hipertrofi ataupun atrofi tidak ditemukan.

Konka dapat menjadi edema dan hiperemis disebabkan oleh banyak penyebab, salah satunya adalah rinitis vasomotor. Rinitis vasomotor adalah suatu keadaan idiopatik yang didiagnosis tanpa adanya infeksi, alergi, eosinofilia, perubahan hormonal dan pajanan obat. Etiologi dan patofisiologi dari rinitis vasomotor belum diketahui secara pasti. ${ }^{10}$

Pada pemeriksaan di SMP Negeri 8 Manado didapatkan hasil mukosa hidung kiri maupun kanan semuanya normal $(100 \%)$ dan pada keduanya tidak ditemukan adanya kelainan mukosa seperti hiperemis dan livide. Pada penelitian yang dilakukan oleh Legoh $^{8}$ terhadap siswasiswi SD Inpres 10/73 Pandu didapatkan hasil yang sama pada kedua mukosa hidung baik kiri dan kanan. Keadaan hiperemis merupakan keadaan abnormal terbanyak pada kedua konka nasal dan ditemukan pada 2 anak $(11,11 \%)$ sedangkan sisanya ditemukan mukosa hidung yang normal pada 16 anak (88,89\%). Mukosa hiperemis bisa terjadi jika terdapat infeksi hidung salah satunya rinitis yang disebabkan oleh infeksi, alergi, atau iritasi sedangkan mukosa livide bisa terjadi karena cairan pada mukosa banyak dan menyebabkan aliran dari mukosa menjadi sedikit sehingga berwarna pucat. ${ }^{11}$

Pada pemeriksaan di SMP Negeri 8 Manado didapatkan hasil sekret hidung kiri maupun kanan semuanya normal (100\%) dan keduanya tidak ditemukan adanya sekret yang serous, mukoid, maupun purulen.

Pada penelitian yang dilakukan oleh Legoh $^{8}$ terhadap siswa-siswi SD Inpres 10/73 Pandu didapatkan hasil yang sama pada kedua mukosa hidung baik kiri dan kanan. Sekret mukopurulen merupakan jenis sekret terbanyak yang ditemukan pada kedua nasal yakni 2 anak $(11,11 \%)$. Jenis sekret lain berupa seropurulen dan purulen ditemukan masing-masing 1 anak $(5,56 \%)$. Sisanya 14 anak $(77,78 \%)$ tidak ditemukan adanya sekret atau normal. Sekret mukopurulen merupakan sekret yang bersifat kental dan lengket. Biasanya terjadi pada kasus inflamasi pada nasal salah satunya rinitis alergi dan rinitis vasomotor. $^{10}$

Pada pemeriksaan di SMP Negeri 8 Manado, didapatkan hasil sebagian besar septum normal dengan persentase pada hidung kiri $100 \%$, dan pada hidung kanan 96,87\%. Terdapat kelainan septum berupa deviasi pada hidung kanan dengan persentase $3,13 \%$ sedangkan pada hidung kiri tidak ada deviasi. Tidak terdapat kelainan septum lainnya seperti abses dan hematoma. Pada penelitian yang dilakukan oleh Legoh $^{8}$ terhadap siswa-siswi SD Inpres 10/73 Pandu didapatkan hasil kedua septum kiri dan kanan semua normal $(100 \%)$ dan pada keduanya tidak ditemukan kelainan berupa deviasi, abses atau hematoma. 
Salah satu kelainan pada septum yaitu deviasi septum. Bentuk normal dari septum nasi yaitu lurus di tengah rongga hidung tetapi pada orang dewasa biasanya septum nasi tidak lurus sempurna di garis tengah. Deviasi septum yang ringan tidak akan mengganggu tetapi bila deviasi itu cukup berat dapat mengakibatkan penyempitan pada satu sisi hidung; hal ini dapat mengganggu fungsi hidung dan menyebabkan komplikasi. ${ }^{12}$

Setelah dilakukan anamnesis dan pemeriksaan lanjut pada salah satu responden yang mengalami deviasi septum, ternyata tidak ditemukan riwayat trauma sehingga dicurigai deviasi septum tersebut merupakan kelainan kongenital. Selain itu tidak ditemukan adanya gejala-gejala yang mengganggu aktivitas sehari-hari.

Selain disebabkan oleh kelainan kongenital, trauma juga dapat menyebabkan deviasi. Melalui berbagai fase perkembangan komponen tulang dan tulang rawan selama pertumbuhan septum, hanya pada sebagian kecil orang, dinding hidung terbentuk tepat di tengah; pada sebagian besar orang, septum sedikit tertekuk. Pada kebanyakan kasus, tekukan tersebut tidak menimbulkan gejala namun bila deviasi lebih mencolok, dapat terjadi pergeseran saluran hidung ke satu sisi. ${ }^{13}$

Terdapat beberapa bentuk deformitas septum yaitu: 1) deviasi berbentuk huruf $\mathrm{C}$ atau $S$; 2) bentuk deformitas dislokasi yaitu bagian bawah kartilago septum keluar dari krista maksila dan masuk ke dalam rongga hidung; 3) penonjolan tulang atau tulang rawan septum, bila memanjang dari depan ke belakang disebut krista, dan bila memanjang sangat runcing dan pipih disebut spina; dan 4) deviasi atau krista septum bertemu dan melekat dengan konka dihadapannya disebut sinekia. ${ }^{12}$

Deviasi terutama bermanifestasi klinis sebagai gangguan pernapasan tetapi fungsi penghidu di hidung juga dapat terganggu akibat obstruksi. Selain itu, sering terjadi peradangan residif di rongga hidung dan sinus paranasal, nyeri kepala, bisa sampai terjadi epistaksis berulang. Hanya deviasi yang menimbulkan gejala memerlukan penatalaksanaan dan terapi pilihan ialah septumplasti. $^{13}$

Pada pemeriksaan di SMP Negeri 8 Manado didapatkan semua hasil normal $(100 \%)$ dan di kedua hidung tidak ditemukan adanya post nasal drip. Pada penelitian sebelumnya yang dilakukan oleh Legoh $^{8}$ terhadap siswa-siswi SD Inpres 10/73 Pandu didapatkan hasil semua responden normal (100\%) dan tidak ditemukan adanya post nasal drip. ${ }^{8}$

Penelitian terhadap 32 responden, menunjukkan yang terbanyak yaitu hasil normal baik pada hidung kiri maupun hidung kanan. Dari keseluruhan hasil penelitian ini didapatkan bahwa status kesehatan hidung pada siswa-siswi Sekolah Menengah Pertama Negeri 8 Manado yaitu baik. Beberapa faktor yang berperan misalnya faktor lingkungan dan faktor kesadaran orang tua siswa-siswi SMP Negeri 8 Manado tentang pentingnya menjaga kesehatan dan keberersihan lingkungan.

\section{SIMPULAN}

Berdasarkan hasil keseluruhan pemeriksaan dapat disimpulkan bahwa siswasiswi di Sekolah Menengah Pertama Negeri 8 Manado mempunyai kesehatan hidung yang baik.

\section{SARAN}

Perlu dilakukan penelitian lebih lanjut lagi mengenai kesehatan hidung agar dapat membantu dalam mendeteksi dini gangguan hidung serta dapat membantu dalam pencegahan gangguan hidung.

Untuk penderita dengan gangguan hidung sebaiknya dilakukan pemeriksaan lebih lanjut ke bagian THT-KL dan konsultasi ke dokter spesialis THT-KL agar segera mendapatkan penanganan dan pengobatan yang lebih memadai.

\section{DAFTAR PUSTAKA}

1. Maulana HDJ. Promosi kesehatan. Jakarta: EGC, 2009; p. 5.

2. Budiman S. Ilmu Kesehatan Masyarakat: dalam konteks kesehatan lingkungan. Jakarta: EGC, 2010. Available from: 
http://e-journal.kopertis4.or.id/file/15/ \%20Kesehatan\%20Lingkungan.pdf.

3. Adams GL, Boies LR, Higler PA. Buku Ajar Penyakit THT (6th ed). Jakarta: EGC, 2007.

4. Soepardi EA, Iskandar N, Bashiruddin J, Restuti RD. Buku Ajar Ilmu Kesehatan Telinga Hidung Tenggorok Kepala \& Leher (7th ed). Jakarta: Badan Penerbit Fakultas Kedokteran Universitas Indonesia, 2012.

5. HTA Indonesia. Functional endoscopic sinus surgery in Indonesia. [Internet]. 2006 [cited 2016 August 25]. Available from: http://buk.depkes. go.id/index.php

6. Jáuregui I, Mullol J, Dávila I, Ferrer M, Bartra J, del Cuvillo A, et al. Allergic rhinitis and school performance. 2009 [cited 2016 August 25]. Available from: http://www.ncbi.nlm.nih.gov/pubmed $/ 19476052$

7. Sastra S, Irsa L, Loebis MS, Evalina R. Number of siblings and allergic rhinitis in children. Volume 56. 2016 January [cited 2016 August 25]. Avalaible from: https://paediatricaindonesiana.org/ind ex.php/paediatrica- indonesiana/article/view/71

8. Legoh A. Kesehatan hidung siswa sekolah dasar inpres 10/73 Pandu [Skripsi]. Manado: Universistas Sam Ratulangi; 2015.

9. Peraturan Menteri Kesehatan Republik Indonesia No.5 Tahun 2014, Panduan praktik klinis bagi dokter di fasilitas pelayanan kesehatan primer. [Cited : 2016 september 1]. h. 293-4

10.Irawati N, Poerbonerogo NL, Kasakeyan E. Rinitis vasomotor. Soepardi E, editor. Buku Ajar Ilmu Kesehatan Telinga Hidung Ttenggorok Kepala \& Leher (7th ed). Jakarta: Badan Penerbit Fakultas Kedokteran Universitas Indonesia, 2012; p. 113-4

11.Lund VJ. Acute and chronic nasal disorders. In: Ballenger's Otorhinolaryngology Head and Neck Surgery (16th ed). Ontario: BC, Decker Inc, 2003; p. 748-66.

12.Nizar NW, Mangunkusomo E. Kelainan septum. Soepardi E. Buku Ajar Ilmu Kesehatan Telinga Hidung Tenggorok Kepala \& Leher (7th ed). Jakarta: Badan Penerbit Fakultas Kedokteran Universitas Indonesia, 2012; p. 104.

13.Nagel P, Gurkov R. Dasar-dasar Ilmu THT (2nd ed). Jakarta: EGC, 2012; p. 48. 